\title{
Preparation of Autologous Platelet Rich Plasma in Kathiawari and Thoroughbred Horses
}

\author{
K. Balamurugan*, Mala Shammi, Ravi Sundar George, \\ T.A. Kannan and R. Sivashankar \\ Department of Veterinary Surgery and Radiology, Madras Veterinary College, Chennai, India \\ *Corresponding author
}

\section{A B S T R A C T}

\section{Keywords}

Horse, Platelet rich plasma, Double centrifugation method

Article Info

Accepted:

12 March 2019

Available Online:

10 April 2019
Platelet rich plasma (PRP) is a newly emerging autologous product in regenerative medicine. There are various methods of preparation available worldwide. But still there is no unique method for preparation of platelet rich plasma. Autologous platelet rich plasma is safe from disease transmission, immune reaction and cross contamination. Platelet rich plasma is a blood derivative which is prepared by different centrifugation method generally greater than two to four times higher when compared with baseline value. In this study, platelet rich plasma was prepared by double centrifugation method. There was a significant increase of platelets in PRP when compared to whole blood.

\section{Introduction}

PRP has a pool of growth factors like platelet derived growth factor (PDGF), transforming growth factor (TGF-ß), vascular endothelial growth factor (VEGF) as well as cytokines such as platelet factor-4 (PF4) and CD40L.

They are widely used in dental implant surgery, orthopaedic surgery, muscle/tendon repair, osteoarthritis and skin ulcer (Anituaet al., 2004). Platelet degranulation releases the growth factors and other substances. These growth factors promote tissue repair and influence the reactivity of vascular and other blood cells in inflammation and angiogenesis (Fortier and Smith, 2008).

\section{Materials and Methods}

Total of six horses were included in this study. They were free from any systemic diseases and had normal body condition. Fifteen milliliters of whole blood was collected in EDTA vials by using 16 gauge needled syringe (Amaral et al., 2016) from jugular vein of each horse.

The blood was transferred into $15 \mathrm{~mL}$ graduated centrifuge tube and centrifuged at $120 \mathrm{~g}$ for 5 minutes by using refrigerated Eppendorf centrifuge $5430 \mathrm{R}$ at $4^{\circ} \mathrm{C}$ (Bi et al., 2010). The first $50 \%$ of the top supernatant plasma fraction adjacent to the buffy coat was collected and centrifuged at $240 \mathrm{~g}$ for 5 minutes. The bottom fourth was considered as 
pure platelet rich plasma (P-PRP) (Rios et al., 2015). The process was carried out within half an hour after blood collection.

The platelet concentration was analyzed using Auto Hematology Analyzer (mindray BC2800Vet). The whole blood and PRP ratio was calculated as followed by Bosch et al., (2010).

Platelet count of PRP

Platelet count of whole blood

\section{Results and Discussion}

The mean platelets and leukocytes concentration of whole blood, first centrifuge and second centrifuge is given in table 1 . The platelet concentration was increased ranging from 2.1 to 3.4 fold from whole blood concentration. Statistical analysis revealed a highly significant increase $(\mathrm{P}<0.01)$ in platelet concentration in second centrifuge from whole blood. PRP of first and second centrifuge were stained with Giemsa stain (Figure 1).

Table.1 Platelet and leukocyte concentration in PRP

\begin{tabular}{|c|c|c|c|c|c|c|c|}
\hline & \multicolumn{3}{|c|}{ Platelets } & \multicolumn{3}{c|}{ Leukocytes } \\
\hline $\begin{array}{c}\text { Horse } \\
\text { No }\end{array}$ & $\begin{array}{c}\text { Base } \\
\text { value }\end{array}$ & $\begin{array}{c}\text { First } \\
\text { centrifuge }\end{array}$ & $\begin{array}{c}\text { Second } \\
\text { centrifuge }\end{array}$ & $\begin{array}{c}\text { P:L } \\
\text { ratio }\end{array}$ & $\begin{array}{c}\text { Base } \\
\text { value }\end{array}$ & $\begin{array}{c}\text { First } \\
\text { centrifuge }\end{array}$ & $\begin{array}{c}\text { Second } \\
\text { centrifuge }\end{array}$ \\
\hline $\mathbf{1}$ & 131000 & 529000 & 450000 & 3.4 & 8500 & 22100 & 18600 \\
\hline $\mathbf{2}$ & 140000 & 412000 & 345000 & 2.5 & 8400 & 9000 & 7000 \\
\hline $\mathbf{3}$ & 124000 & 374000 & 355000 & 2.9 & 4200 & 10500 & 8500 \\
\hline $\mathbf{4}$ & 111000 & 381000 & 252000 & 2.3 & 9300 & 11600 & 5500 \\
\hline $\mathbf{5}$ & 175000 & 521000 & 360000 & 2.1 & 8500 & 3400 & 3300 \\
\hline $\mathbf{6}$ & 201000 & 471000 & 412000 & 2.1 & 11300 & 30000 & 24000 \\
\hline
\end{tabular}

Table.2 Mean \pm SE Platelets and WBC concentration

\begin{tabular}{|l|c|c|c|c|}
\hline & Whole blood & First centrifuge & Second centrifuge & P value \\
\hline Platelets & $147000 \pm 13940.34^{\mathrm{a}}$ & $448000 \pm 28095.08^{\mathrm{c}}$ & $362333.33 \pm 27498.69^{\mathrm{b}}$ & $\mathbf{0 . 0 0 1} * *$ \\
\hline WBC & $8366.67 \pm 946.46$ & $14433.33 \pm 3982.68$ & $11150 \pm 3358.65$ & $\mathbf{0 . 4 5 9}^{\text {NS }}$ \\
\hline
\end{tabular}

* Significant difference $\mathrm{P}<0.05$, ** Highly significant $\mathrm{P}<0.01$ and

${ }^{\mathrm{NS}}$ Non-significant $\mathrm{P}>0.05$, each group was significant from each other

Fig.1 Photomicrograph showing platelets (arrows) and leukocytes after first centrifuge (1a) and second centrifuge (1b) x 1000- Giemsa staining

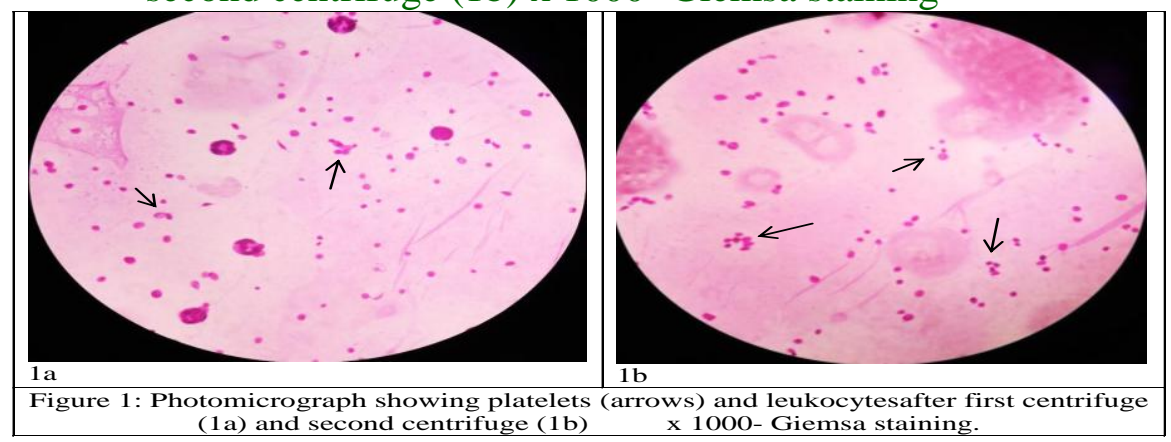

This concentration was used intra-articularly in the same horse for osteoarthritis. No 
adverse effects were notice with this leukocyte concentration. In conclusion, this type of double centrifugation method provide adequate amount of platelet concentration with reduced leukocyte concentration. This PRP preparation is simple, cost effective and non-invasive procedure and this can be prepared at the time of use.

\section{Acknowledgement}

Authors acknowledge, The Dean and Director of clinics, Madras Veterinary College, Tamil Nadu Veterinary and Animal Sciences University for providing financial support to carry out the study.

The authors thank DBT (Department of Biotechnology) for providing centrifuge machine under the scheme "Autologous platelet rich plasma seeded on Biodegradable ECM for regenerative therapy of musculoskeletal disorders in companion animals".

\section{References}

Amaral, R.J.F.C, Silva, N.P., Haddad, N.F., Lopes, L.S., Ferreira, F.D., Filho, R.B., Cappelletti, P.A., de Mello, W., Spinetti, E.C. and Balduino, A. 2016. Platelet rich plasma obtained with different anticoagulants and their effect on the platelet numbers and mesenchymal stromal cells behavior in vitro. Stem Cells International, pp.1-11.

Anitua, E., Andia, I., Ardanza, B., Nurden, P and Nurden, A.T. 2004.Autologous platelets as a source of proteins for healing and tissue regeneration. Thrombosis and Haemostasis, 91, 415.

Bi, L., Cheng, W., Fan, H., and Pei, G. 2010. Reconstruction of goat tibial defects using an injectable tricalcium phosphate/chitosan in combination with autologous platelet rich plasma. Biomaterials, 31, 3201-3211.

Bosch, G., van Schie, H.T.M., de Groot M.W, Calby, J.A., van de Lest, C.H.A, Barneveld, A. and van Weeren, P.R. 2010. Effects of platelet-rich plasma on the quality of repair of mechanically induced core lesions in equine superficial digital flexor tendons: A placebo-controlled experimental study. Journal of Orthopaedic research, 28, 211-217.

Fortier, L.A. and Smith, R.K.W. 2008. Regenerative medicine for tendinous and ligamentous injuries of sport horses. Veterinary Clinics of North America: Equine practice,24, 191-201.

Ríos, D.L., Lopez,C. and Carmona, J.U. 2015. Platelet-Rich gel supernatants stimulate the release of antiinflammatory proteins on culture media of normal equine synovial membrane explants. Veterinary Medicine International, http://dx.doi.org/10.1155/2015/547052 pp.1-9.

\section{How to cite this article:}

Balamurugan, K., Mala Shammi, Ravi Sundar George, T.A. Kannan and Sivashankar, R. 2019. Preparation of Autologous Platelet Rich Plasma in Kathiawari and Thoroughbred Horses. Int.J.Curr.Microbiol.App.Sci. 8(04): 1689-1691. doi: https://doi.org/10.20546/ijcmas.2019.804.197 